\title{
O AGRICULTOR FAMILIAR DIANTE DA LEGISLAÇÃO AMBIENTAL: Reflexões à Luz do "Direito à Dignidade"
}

\author{
http://dx.doi.org/10.21527/2176-6622.2020.54.192-204
}

Recebido em: 1ㅇ/4/2020

Modificações solicitadas em: 26/6/2020

Aceito em: 14/7/2020

\section{RESUMO}

Este trabalho teve por objetivo refletir a respeito da vulnerabilidade dos agricultores familiares na esfera judicial. Trabalhou-se com a hipótese de que a fragilidade social e econômica que atinge este segmento estende-se ao âmbito judicial. Para a obtenção dos dados foram realizadas entrevistas não estruturadas com agricultores familiares da região em estudo e com agentes ambientais. Além disso, foram coletados dados por meio de consulta realizada na sede da Polícia Militar do Meio Ambiente, do município de Viçosa - MG, na 2ª Promotoria Cível e nas 1a e 2a Varas Criminais, todas da Comarca de Viçosa - MG. Concluiu-se que a posição de desvantagem dos agricultores familiares, que é nítida em termos de segmento da economia, existe também nas relações judiciais. Ficou evidenciada a incapacidade de tais sujeitos utilizarem os mecanismos legais de defesa, como a defesa técnica realizada por advogado ou mesmo o acesso aos recursos, o que representa um grande desafio para o poder público, responsável por exercer os deveres de tutela para assegurar dignidade e respeito a todos os cidadãos.

Palavras-chave: Legislação. Agricultor. Dignidade.

\section{THE FAMILY FARMER IN FRONT OF ENVIRONMENTAL LEGISLATION: REFLECTIONS IN THE LIGHT OF 'RIGHT TO DIGNITY’}

\section{ABSTRACT}

This paper aimed to reflect on the vulnerability of family farmers in the judicial sphere. We worked with the hypothesis that the social and economic fragility that affects this segment extends to the judicial sphere. To obtain the data, unstructured interviews were conducted with family farmers in the region under study and with environmental agents. In addition, data were collected through consultation carried out at the headquarters of the Military Police of the Environment, in the municipality of Viçosa - MG, at the 2nd Civil Prosecutor's Office and at the 1st and 2nd criminal courts, all in the District of Viçosa - MG. It was concluded that the disadvantaged position of family farmers, which is clear in terms of the segment of the economy, also exists in judicial relations. It was evidenced the inability of such subjects to use the legal defense mechanisms, such as the technical defense performed by a lawyer or even access to resources, which represents a great challenge for the public power, responsible for exercising the guardianship duties to ensure dignity and respect for all citizens.

Keywords: Legislation. Farmer. Dignity.

\section{SUMÁRIO}

1 Introdução. 2 A vulnerabilidade no campo social. 3 Discursos e percepções sobre a lei. 3.1. O que pensam os agricultores. 3.2 Perspectivas dos agentes ambientais. 4 Reflexões à luz do "Direito à dignidade". 5 Considerações finais. 6 Referências. 


\section{INTRODUÇÃO}

A concepção de vulnerabilidade não está relacionada apenas à ausência ou precariedade de acesso à renda, mas também às fragilidades de vínculos relacionais e de acesso a bens e serviços. Nesse sentido, este trabalho tem o objetivo de refletir a respeito da vulnerabilidade de um segmento específico da agricultura, conhecido como "agricultura familiar", diante do poder do Estado, especialmente considerando, aqui, os embates desse segmento com o poder Judiciário e com os órgãos que atuam como fiscais da lei ambiental.

Considerando o ser humano um fim em sim mesmo, trabalha-se com a hipótese de que, muitas vezes, mesmo no âmbito do poder Judiciário, alguns grupos, entre eles os agricultores familiares, encontram-se nitidamente em condição de desigualdade perante outros grupos e à mercê do poder do Estado, em uma clara violação dos pilares de dignidade que perpassam o ordenamento jurídico brasileiro.

Embora a agricultura familiar englobe segmentos diversos, como extrativistas, assentados, minifundiários, pequenos empresários, agroecologistas e monocultores, para grande parte da população essa denominação refere-se à pequena produção rural, portanto aos estabelecimentos produtores das rendas mais baixas e, também, aqueles de menores extensões de área (NAVARRO; PEDROSO, 2014).

Este conceito que prevalece no imaginário coletivo, porém, encontra justificativa, pois, embora responsável por produzir cerca de $70 \%$ dos alimentos consumidos no país e empregar $74,4 \%$ dos trabalhadores rurais esse segmento enfrenta dificuldades econômicas, e estas, muitas vezes, refletem-se no campo social, inclusive na capacidade de exercício dos direitos.

Este trabalho investigou a respeito dessa vulnerabilidade dos agricultores familiares diante dos órgãos e instrumentos do Estado que se movem quando há algum tipo de infração ambiental. A análise ocorreu a partir de um estudo de campo realizado na Zona da Mata Mineira, uma localidade com forte presença de conflitos entre agricultores e Estado, em razão das características geológicas e das legislações ambientais de âmbitos federal e estadual que vigoram conjuntamente e que trazem limitações nos modos de produção dos agricultores. Estas leis são, especialmente, o Código Florestal, o Código Florestal Mineiro e a Lei da Mata Atlântica.

Para a realização desta pesquisa a metodologia adotada foi basicamente qualitativa, com a utilização de dados primários e secundários, que foram interpretados com o apoio da literatura pertinente, em uma proposta de triangulação de métodos. Para a obtenção dos dados foram realizadas entrevistas não estruturadas com agricultores familiares da região e com agentes ambientais. Além disso, foram coletadas informações por meio de consulta realizada na sede da Polícia Militar do Meio Ambiente, do município de Viçosa - MG, na 2a Promotoria Cível e nas 1a e 2a Varas Criminais, todas da Comarca de Viçosa - MG. O objetivo desses dados foi apresentar um panorama a respeito do número e dos tipos de infrações mais frequentes, em cada município, no período em estudo.

Optou-se por estudar os municípios que compõem a Comarca de Viçosa - MG, na Zona da Mata Mineira. Os municípios são: Viçosa, Coimbra, Cajuri, São Miguel do Anta, Porto Firme e Paula Cândido. Para análise dos processos foi necessário demarcar um período de tempo, no caso os anos de 2011 a 2013, em que foram identificados 240 processos/procedimentos envolvendo agricultores familiares. O marco temporal foi escolhido com vistas a analisar possível influência do Código Florestal, aprovado em 2012.

Diante da impossibilidade de análise de todos os processos, foi realizado o cálculo da amostra válida, considerando uma amostra com 95\% de confiabilidade, e, a partir disso foram analisados, efetivamente, 148 processos/procedimentos.

Antes da realização das entrevistas o projeto foi submetido à apreciação do Comitê de Ética da Universidade Federal de Viçosa e foi aprovado conforme parecer consubstanciado CAAE 34746114.9.0000.5153.

$\mathrm{O}$ artigo está dividido em três partes. Na primeira foram apresentados os dados quantitativos de boletins de ocorrência, processos e procedimentos estudados. Na segunda foram apresentadas as percepções dos agricultores e agentes do Estado a respeito da lei ambiental e, na terceira, foi exposta a reflexão acerca da vulnerabilidade desses agricultores diante do sistema legislativo e judiciário, considerando a premissa de que todo cidadão deve ter o 'direito à dignidade', isto é, ao reconhecimento, ao respeito e à existência digna. 


\section{A VULNERABILIDADE NO CAMPO SOCIAL}

Na Comarca de Viçosa os policiais chegam ao local do fato por meio de notícia-crime, na maior parte das vezes, ou por meio de policiamento ostensivo, ou seja, do trabalho normal de ronda. Constatada a infração, a polícia notifica o infrator a respeito da instauração de um procedimento administrativo, que geralmente tem como consequência a aplicação de uma multa. O Boletim de Ocorrência, lavrado na hora, é encaminhado on-line para a Delegacia da Polícia Civil e para o Ministério Público Estadual.

Cabe ao delegado da Polícia Civil analisar se o fato constitui crime ambiental. Se constituir, deverá ser iniciado um inquérito policial. Concluído o inquérito, ele deverá ser encaminhado ao Ministério Público, órgão responsável para propor a ação penal. O processo surge com a ação penal, pois, ao dar início a ela, o conflito é levado à apreciação do poder Judiciário para que o juiz decida se houve crime e se a pessoa acusada deve ser punida.

Paralelamente a isto, o Ministério Público analisa se o fato causou dano ambiental. Se tiver causado, poderá optar entre propor um Termo de Ajustamento de Conduta (TAC) ou iniciar uma ação civil pública. O Ministério Público tem competência, ainda, para iniciar inquérito civil para apuração de dano ambiental, independentemente de ocorrência de crime ou infração ambiental. Nesses casos, o fato chega ao conhecimento do promotor por meio de notícia-crime.

A possibilidade de mais de um desdobramento da infração ambiental é um dos aspectos mais difíceis de serem compreendidos pelos agricultores, pois, muitas vezes, eles são autuados administrativamente e acreditam que o problema será totalmente solucionado com o pagamento da multa. Após o pagamento, contudo, são surpreendidos com uma notificação para que compareçam à sede do poder Judiciário para realizar um TAC ou recebem uma citação judicial que informa que foi instaurado um processo em que ele é réu. A sensação dos agricultores é a de que estão sendo punidos duplamente ou triplamente pelo mesmo fato.

De acordo com o ordenamento jurídico brasileiro, é possível apresentar defesa contra o auto de infração, no prazo de 20 (vinte) dias, contados da data da notificação do autuado da lavratura do auto de infração. Essa defesa poderá ser elaborada pelo próprio autuado ou por um advogado. Cabe ao autuado a prova dos fatos alegados, entretanto as provas apresentadas pelo autuado poderão ser recusadas, mediante decisão fundamentada da autoridade competente.

Após julgamento da defesa apresentada, o autuado receberá, em sua residência, uma correspondência, contendo um ofício que informará sobre a resposta da defesa. Caberá, ainda, o recurso que poderá ser apresentado no prazo de 30 (trinta) dias, contados da data da notificação do autuado do julgamento da defesa. 0 recurso também poderá ser elaborado pelo próprio autuado ou por advogado.

Apesar da previsão legal, dado o grau de desinformação existente entre os agricultores, a apresentação de defesa e de recurso pelo próprio autuado são muito pouco utilizados. Esta pressuposição foi confirmada pelos técnicos do Instituto Estadual de Florestas (IEF). Segundo o analista ambiental do IEF, "a maior parte dos agricultores autuados paga a multa, sem contestações, de forma parcelada". O senhor Daniel (nome fictício), morador de Córrego Fundo, Viçosa-MG, é um exemplo que parece representar o comportamento comum entre os agricultores da região em relação ao pagamento de multas. Disse ele:

Paguei R\$ $6.000,00$ porque não ajustei advogado. Depois me falaram que se tivesse arrumado advogado, a multa tinha diminuído. Mas eu não arranjei não, porque eu não preciso de advogado. Pra quê advogado? Eu não matei ninguém... (senhor Daniel, agricultor familiar da zona rural de Viçosa- MG).

A partir da fala deste agricultor, duas observações podem ser feitas: a primeira vai ao encontro do estudo de Woortmann (1990), de acordo com o qual a honestidade é um valor a que o camponês dá muita importância. Nesse sentido, "demandar na Justiça" é algo que só deve ocorrer quando não puder ser evitado, pois remete à prática de uma má conduta. Desta percepção decorre a segunda observação, que aponta para o significado social e psicológico do processo na vida desses sujeitos, pois, muito além de ser um contratempo, implica deduções a respeito do indivíduo.

Fica evidenciado, portanto, que, embora existam previsões legais no sentido de facilitar a resolução dos problemas de irregularidade ambiental, existe uma parcela significativa de cidadãos que permanece excluída de tais possibilidades, pois a desinformação e a falta de acesso aos mecanismos de defesa limitam o exercício 
pleno dos direitos. Considerando que acessos e oportunidades são também uma espécie de recurso, nota-se que grupos social e economicamente vulneráveis, como é o caso dos agricultores familiares, encontram mais dificuldades para usufruírem das garantias legais e jurídicas.

As autoridades esforçam-se para atribuir aos agricultores a responsabilidade por não utilizarem as concessões dadas pela lei e por não pleitearem as políticas de que necessitam, afirmando serem os agricultores pessoas "caladas e pouco participativas". Em entrevista o promotor de Justiça da Comarca de Viçosa afirmou que "os agricultores não são organizados, e mesmo quando conseguem se organizar, de alguma maneira, os representantes têm pouca instrução" (Promotor de Justiça da Comarca de Viçosa, entrevista).

$\mathrm{Na}$ Comarca de Viçosa, durante o período de 2011 a 2013, considerando os 240 procedimentos em curso, $65,8 \%$ resultaram em TACs. Destes, 33,5\%, foram cumpridos e $66,5 \%$ tiveram desdobramentos judiciais, com propositura de ações. Logo, não se pode afirmar que a realização do acordo extrajudicial tenha amenizado a situação do agricultor, evitando que este tenha desgastes decorrentes da lentidão e burocracia da Justiça, pois a quantidade de acordos que não foram cumpridos é significativa. As principais razões que justificam o descumprimento dos TACs são as dificuldades em cumprir as medidas ajustadas e o custo que elas envolvem.

De acordo com a pesquisa, entre a ocorrência do fato e a realização do acordo (TAC) decorrem em média 2 anos. Entre a realização do TAC e o termo final do processo passam em média 3 anos, totalizando um período de duração médio para o processo de 5 anos, desconsiderando eventuais recursos. Esse prazo pode variar de acordo com as especificidades do caso, mas o que se pôde notar é que o fator que mais interfere no tempo de duração do processo é a realização da perícia. De acordo com informações obtidas nos próprios autos e confirmadas por funcionários estaduais, a estrutura dos órgãos técnicos estaduais responsáveis pela perícia encontra-se bastante deficitária, de modo que os agentes são insuficientes para o número de solicitações feitas pela Justiça.

\section{DISCURSOS E PERCEPÇÕES SOBRE A LEI}

Os agricultores familiares encontram dificuldades em suas relações com o Estado e com as instituições, devido, principalmente, à escassez de informação e acesso, ao passo que os agentes estatais argumentam que as dificuldades encontradas pelos agricultores estão diretamente ligadas ao perfil introspectivo desses atores sociais. Será apresentado, aqui, um paralelo a respeito da perspectiva dos agricultores sobre o Estado e a lei e, por outro lado, a perspectiva dos agentes estatais sobre o papel do Estado e o comportamento dos agricultores.

\subsection{O que Pensam os Agricultores}

A primeira observação que pode ser feita refere-se ao modo como os agricultores reagiram à pergunta: "O que é o Estado para você?" As primeiras reações observadas eram um riso, acompanhado de uma expressão de quem não sabia responder. Posteriormente, alguns deles falaram: "Isto eu não sei responder, não...", e outros arriscaram algumas respostas como: "é quem manda", "são os grandes", "são aqueles ladrões que não mandam nada pra gente", "é o presidente, o governador". Após um pouco mais de conversa, alguns entrevistados mencionaram certos agentes que poderiam ser considerados "Estado", tais como Emater, juiz, promotor, polícia, IEF. Observa-se que o fato de eles terem mencionado essas autoridades como representantes do Estado deve-se ao fato de a pesquisa ter sido apresentada como investigativa sobre a área ambiental e de toda a conversa que precedeu a essa pergunta ter sido a respeito de meio ambiente e de leis ambientais.

De toda forma, a dificuldade em dizer quem é o Estado ou de mencionar um agente que pudesse representá-lo chama a atenção para a distância que existe entre esse grupo social estudado e a estrutura estatal. Os entrevistados somente associaram aquele ente à imagem de alguém que pune ou que não presta o apoio que deveria prestar.

O senhor Sebastião, do Córrego de São João (Viçosa, MG), disse: "Falta apoio do Estado. O Estado é o presidente que deve dar um apoio, porque viver na roça tá ruim."

O senhor Roberto, também do Córrego de São João, afirmou: "O poder público deveria dar mais informação e apoio. Vem dinheiro pra isso." 
Sobre esse aspecto vale mencionar Fleury (1994, p. 14), de acordo com a qual "Na percepção do Estado como instrumento, este se acha reduzido a um instrumento da classe dominante na consolidação de sua dominação política e exploração econômica". Para Fleury (1994), não existe maneira de um Estado, cuja natureza é classista e a ocupação dos postos é feita pelos membros da classe dominante, contemplar, em suas políticas, os interesses das classes dominadas. Esse aspecto reduz o Estado e toda a sua política a um mero elemento da estratégia de exploração e/ou de legitimação do exercício da dominação. É dessa forma mencionada por Fleury (1994) que o Estado é compreendido pelos agricultores, como um ente que os explora, no qual eles não acreditam.

Ainda a respeito das percepções gerais, merece destaque o fato de quase todos os entrevistados terem mencionado que reconhecem que a lei para proteger o meio ambiente é necessária.

O senhor Alessandro, do Córrego de São João, disse: “Que deve de ter lei, acho que deve de ter, se não ia faltar água pra todo mundo. Mas tinha que ter diferença: uma lei para rico e uma para pobre."

No mesmo sentido, o senhor José Mauro, da Comunidade de Santa Tereza (Viçosa, MG), falou:

Se a lei for cumprida acho que faz diferença, mas ela deveria ser diferente para o pequeno porque para nós é mais difícil de cumprir. Do jeito que é, prejudica a minoria para ajudar a maioria porque atrapalha o agricultor para ajudar a população em geral.

Dois aspectos podem ser observados como recorrentes nas respostas a essa pergunta: a menção ao tratamento desigual que é dado aos agricultores "ricos" e "pobres" e a preocupação em relação à água. Os agricultores compreendem que os "ricos" têm mais facilidade para se adequarem às exigências legais e, também, para se livrarem das punições, uma vez que podem pagar por consultorias e/ou contratar os melhores advogados. Além disso, acreditam que os órgãos de fiscalização são condescendentes com os "ricos". "O Brasil não tem lei, tem é dinheiro, porque rico paga e pobre leva multa".

Todos os entrevistados mencionaram que a escassez de água traz consequências graves para a agricultura e para a vida. O senhor Zizim, do Córrego de São João (Viçosa, MG) observou: "[...] acho que tem que proteger muito as nascentes, porque a água faz muita falta... Aqui nunca faltou, graças a Deus! Mas o que a gente faz sem a água? Nada!"

O senhor João, da Sucanga (Viçosa, MG) declarou:

Uma nascente é a coisa mais importante em uma propriedade. Aqui, na minha, eu não tenho, mas meu sonho era ter nem que fosse uma só... Se eu tivesse, eu protegia ela, cercava direitinho e não deixava animal chegar...

Ressalta-se que no período de realização das entrevistas a região vivenciava uma grave crise hídrica e, por essa razão, a água tornou-se uma preocupação premente, o que pode justificar respostas tão enfáticas sobre o assunto. Van Der Ploeg (2009) observa que as economias camponesas possuem um padrão em que os recursos naturais são o principal capital disponível e não têm um caráter mercantil; eles estão ligados à sobrevivência do grupo. Logo, em contextos de escassez, tais recursos ganham importância ainda maior.

$O$ fato de recursos naturais serem fundamentais para a sobrevivência do grupo pode ampliar ainda mais o risco da degradação, que pode advir da superexploração. Lembra-se, aqui, de um dos estudos de Corrêa (2006), em que um agricultor afirmou que "Sem poder utilizar as APPs de margens de rio seria melhor abandonar a propriedade".

Quando perguntado se os agricultores procuram se adaptar às exigências da legislação, a totalidade deles respondeu que não. O senhor Zizim, do Córrego de São João, afirma:

Tem coisa que, pra mim, não influi, nem contribui. O que é mato tem que ser mato, e o que é água tem que ser água; mas tem umas "frescuragens" que a gente tem que passar por cima; se não, até para bater pasto tem que pegar guia!

No mesmo sentido foi a seguinte a resposta do senhor Filim, de Pedra Redonda (Viçosa, MG): "Não é pra tudo que eu procuro pegar guia, não. Guia é demorado; e tudo é, na cidade...".

Em relação ao fato de, algumas vezes, serem surpreendidos pela fiscalização e receberem multa, sempre justificam, dizendo que as exigências são excessivas e que os vizinhos fazem "denúncias" "por maldade". 
O senhor Zizim, de Córrego de São João, disse: "Muita exigência não ajuda muito, porque a gente respeita mais ou menos. Isso é mais pra deixar a gente de cabeça quente..."

Dois aspectos merecem ser observados aqui. O primeiro, relativo ao descrédito dos agricultores em relação ao Estado que os explora e o segundo, referente ao comportamento de resistência, desenvolvido por eles como uma forma de reação ao constante abandono e exclusão. Segundo Niederle e Grisa (2008), a resistência é uma forma que os atores sociais desenvolvem para se relacionar com o poder.

Acresce-se a esses dois elementos a desinformação dos agricultores. Restou muito claro que eles possuem pouco esclarecimento sobre seus direitos e deveres. A respeito do Código Florestal, sabem aquilo que já "ouviram falar", e que se refere basicamente à obrigatoriedade de "ter que ter reserva legal na propriedade", "ter que cercar as nascentes" e "ter que pegar guia para fazer tanque de peixe". Mesmo sobre esses aspectos mais comentados o conhecimento é bastante superficial. A respeito da existência de um novo Código, a quase totalidade dos entrevistados afirmou que não sabia dessa nova lei: "Essa lei ainda não chegou aqui não".

Segundo Dewey (1970), as diferenças econômicas reagem contra a igualdade de oportunidades, na medida em que constrangem a participação dos indivíduos nos processos coletivos de resolução de problemas sociais. Desse modo, para que as garantias da lei possam ser plenamente usufruídas, é necessário que as desigualdades econômicas e as deficiências de informação e de acesso sejam superadas.

O próprio promotor de Justiça, ao falar a respeito do perfil do agricultor que responde a processo, afirmou:

O perfil é majoritariamente de pessoas pobres, até paupérrimas e desinstruídas, à mercê do suporte estatal. Não sabemos se há uma predileção da polícia por esse público ou se existe um receio de atuação quando o poder econômico é expressivo.

A fala do promotor deixa clara a ideia de Souza (2006), de acordo com o qual o status do indivíduo na sociedade depende de sua qualificação, posição e salário. Essa "tríade meritocrática" atribui ao sujeito identidade, autoestima e legitimação social. Segundo Souza (2006), a qualificação, que reflete a importância do conhecimento, é o aspecto mais relevante que condiciona os outros dois. Apenas quando essas precondições estão dadas é que o indivíduo obtém sua identidade pessoal e social de forma completa. De acordo ainda com este autor (2006), o status que cada um ocupa na sociedade legitima o acesso diferencial permanente a oportunidades na vida e à apropriação de bens escassos.

A percepção aqui, portanto, é de que as dificuldades enfrentadas pelos agricultores para se adequarem à lei e para acessarem os órgãos prestadores de assistência funcionam como um incentivo para permanecerem com as mesmas práticas, algumas vezes sabidamente ilegais.

Esse aspecto fica bastante evidente na fala do senhor Antônio, da Pedreira (Viçosa, MG):

Eu limpei a capoeira, um pedacinho à toa, para plantar e tratar da família. Eles vieram aqui e me multaram. A multa foi a mesma do que se eu tivesse cortado tudo. Quando eles foram embora, eu fui lá e cortei o resto; já tinha me multado mesmo... [risos].

Muitos agricultores disseram que "não vale a pena ficar esquentando cabeça com isto [a lei] não...".

O mesmo senhor Antônio disse ainda:

Tem que exigir muito é dos grandes, de quem tem muita terra; mas deles, eles não exigem... A vida aqui é difícil, só quem tá aqui é que sabe. O Estado não faz nada pra gente, não. Ninguém vem aqui dar nada, a gente é que tem que lutar...

Essas falas evidenciam a resistência como instrumento de defesa, pois é a única forma que esse grupo, continuamente excluído dos ativos e acessos, encontra para lutar contra um Estado que não os socorre. De acordo com Niederle e Grisa (2008, p. 8), "a resistência é uma forma de os atores sociais intervirem no curso dos acontecimentos, pois faz com que indivíduos destituídos de capacidades transformem-se em atores".

As alegações de falta de apoio por parte do Estado e de que este "só chega pra multar" são bastante recorrentes. De acordo com os entrevistados, sempre que procuram os serviços do Estado recebem a resposta de que a prestação não é possível, seja porque faltam recursos ou porque faltam técnicos. Apesar disso, as providências para punir são rápidas. 
Quando perguntado se os agricultores conheciam algum órgão ambiental e se já tinham tido algum contato com algum deles e em que condições isto teria ocorrido, as respostas mais frequentes foram: "Já ouvi falar, mas não sei para que serve".

A dona Maria de Lourdes observa: "Eu vejo eles passarem por aqui; acho que é para multar os outros aí, mas eu nem conheço."

Alguns agricultores, como o senhor Sebastião, disseram que já haviam procurado o IEF para que autorizasse o desmatamento na propriedade e que esse tinha sido o único contato que teve com o órgão.

A percepção dos agricultores, portanto, é de que, se for para receberem apoio, recursos, informações, o Estado age como se eles não existissem, mas, por outro lado, são eles os mais atingidos pelas medidas de punição, seja porque são pobres, seja porque não possuem muita informação ou porque não podem pagar advogado. Pode-se pensar, então, a respeito de uma forma de "invisibilidade seletiva" ou "invisibilidade de dupla face" de que os grupos econômica e socialmente vulneráveis são vítimas. Embora a lei seja igual para todos, a ação do Estado e das instituições depende das características do sujeito.

Os agricultores mencionaram, ainda, o fator "custo" como um elemento que dificulta a regularização das atividades. Ressalta o senhor Antônio, de Pedra Redonda (Viçosa, MG): "Tudo é demorado e tem que pagar". Muitos agricultores associaram o argumento financeiro com os fatores "falta de tempo" e "falta de mão de obra". Eles afirmam que, por não disporem de força de trabalho suficiente, seja em razão da escassez, tamanho da família, seja por causa do custo, não podem perder tempo para resolver questões na cidade. Assim, a burocracia e o custo das taxas encorajam o agricultor a permanecer em condição irregular.

Por fim, menciona-se um último aspecto a respeito das entrevistas em que se pôde perceber algumas interferências que as punições e a situação de estar "respondendo a processo" são capazes de trazer para os agricultores em âmbito social. São reflexos ligados ao sentimento de vergonha do agricultor perante sua comunidade.

A respeito das consequências sociais e psicológicas trazidas por um processo judicial, Dworkin afirma que os processos judiciais são importantes em outro aspecto que não pode ser avaliado em termos de dinheiro, nem mesmo de liberdade. Segundo ele, "há inevitavelmente uma dimensão moral associada a um processo judicial, pois o juiz não apenas decide quem vai ter o quê, mas quem agiu bem ou quem cumpriu com suas responsabilidades de cidadão" (DWORKIN, 2007, p. 3). Muitas vezes, as penalidades consideradas brandas pelo Judiciário, especialmente porque não resultaram em cerceamento de liberdade para o réu, trazem outras consequências não jurídicas, mas também gravosas, se considerado o contexto social em que o indivíduo está inserido. No caso dos agricultores, a dimensão moral da pena costuma ser até mais onerosa, dado o valor que esse grupo atribui à honestidade e à honra.

Ihering (1978) enfatiza o valor da honra para o camponês. Segundo ele, "trabalho e propriedade constituem a honra do camponês (IHERING, 1978, p. 51). No mesmo sentido, Woortmann (1990), que compreende a relação do camponês com a terra como uma relação de valor moral, ressalta que, para ele , "terra, trabalho e honra" constituem o fundamento da existência.

Durante as entrevistas, a maior parte dos agricultores que já havia sido multada ou respondido a algum processo por infração ambiental afirmou que não repetiria a conduta. Isso indica que, apesar da resistência, possuem um temor, pois reconhecem que as consequências pelas condutas ilegais os prejudicam. Indica também que, quando se propõe analisar os impactos de um determinado fator (nesse caso, a legislação) em relação aos meios de vida, não existe o pressuposto de que tais interferências serão sempre ruins. Elas também podem ser positivas, por conduzirem a uma mudança de postura no sentido da adoção de práticas mais aceitáveis.

Conforme demonstrado, as interferências da legislação sobre os meios de vida dos agricultores vão além dos aspectos financeiros. Isso porque meios de vida não são apenas as formas de obtenção do sustento material, mas todo um conjunto de direitos, valores, costumes, que fazem do indivíduo quem ele é e que dão sentido ao seu mundo. Apesar da tendência, nos estudos sobre meios de vida, de concentrar o enfoque em capitais e recursos, outros reflexos, relacionados à falta de oportunidades, de informações, de apoio e a formas de assegurar vantagens a grupos específicos, podem interferir e trazer consequências que vão além das dificuldades de terem de sobreviver em condições economicamente difíceis. 
A seguir serão apresentados os pontos de vista dos agentes ambientais para que possam servir de contraponto aos argumentos apresentados pelos agricultores. Observa-se que, em muitos casos, as percepções dos dois grupos aproximam-se, enquanto, em outros, as visões revelaram-se diametralmente opostas.

\subsection{Perspectivas dos Agentes Ambientais}

Na visão das autoridades públicas envolvidas nos processos relativos a infrações ambientais, a falta de acesso às informações é um dos fatores responsáveis pelo número de ocorrências, mas em geral compreendem e explicam essa situação como um problema individual. Na verdade, o que se observa é que o acesso à informação e à extensão rural é um problema que atinge todo o segmento e causa muitos prejuízos, entre eles o desfecho judicial dos conflitos ambientais. Tal comportamento dos agentes do Estado contribui para justificar um sistema de injustiças e também para legitimar a exclusão às oportunidades e acessos que a desigualdade institui, numa perspectiva de compreensão do direito como instrumento de poder.

Embora saibam que a razão para a não utilização dos recursos seja a falta de informação dos agricultores, que funciona como uma limitação não apenas para a utilização dos instrumentos legais, como também para que busquem ajuda, continuam associando tais condutas ao perfil "carrancudo" do camponês. Sobre este aspecto, vale mencionar as reflexões de Freire a respeito das razões prováveis do comportamento fechado do agricultor, em que o autor afirma que os camponeses não recusam o diálogo porque sejam, por natureza, refratários a ele. Há razões de ordem histórica, sociológica, cultural e estrutural que explicam sua recusa ao diálogo (FREIRE, 1983). Freire, porém, observa que "para que os homens simples sejam tidos como absolutamente ignorantes, é necessário que haja quem os considere assim. Estes, como sujeitos desta definição, necessariamente a si mesmos se classificam como aqueles que sabem" (1983, p. 30).

Segundo Souza (2006), o valor diferencial entre os seres humanos subsiste de forma inarticulada em todas as nossas práticas institucionais e sociais. Existe uma ligação subliminar destas intencionalidades individuais nos diversos contextos do cotidiano. Dessa forma, "há uma parcela de pessoas que são consideradas 'subgente', mas esta dimensão é subliminar, implícita e se mostra a partir de signos sociais aparentemente sem importância". Nas palavras de Souza (2006), "o que existe aqui são acordos e consensos sociais mudos e subliminares, mas por isso mesmo tanto mais eficazes, que articulam, como que por meio de fios invisíveis, solidariedades e preconceitos arraigados".

Percebeu-se certa aproximação entre os dois grupos em estudo (agricultores e autoridades públicas) quando perguntados a respeito das razões que dificultam o cumprimento da legislação. Os agricultores ressaltaram a questão do excesso de exigências; já os agentes ambientais reforçaram a complexidade do conjunto de leis ambientais. Nesse ponto, vale observar que todos os agentes estatais entrevistados destacaram o fato de não serem eles os autores das leis, nem os responsáveis pela existência de tantos instrumentos jurídicos (leis, regulamentos, portarias) em vigor. Argumentaram, também, que, na condição de agentes públicos que são, têm o dever de buscar os caminhos da legalidade e exigir o cumprimento da norma, independentemente de outras questões. $O$ consenso em relação a esse aspecto deixa claro que existe o reconhecimento de que a lei ambiental é complexa e que isto dificulta o seu cumprimento.

\section{O promotor de Justiça da Comarca de Viçosa afirmou:}

Ninguém pode se escusar de cumprir a lei, o que significa que a ignorância não pode servir de desculpa para deixar de cumprir o que a lei determina. Apesar disso, sabe-se que os agricultores familiares não dispõem de muita formação/informação, de modo que fiquemos tranquilos que eles conhecem a lei. Nós mesmos não a conhecemos completamente, devido a abundância de leis.

Ambos os grupos mencionaram também, como um dos fatores que dificulta a adequação à norma legal, a questão do custo para o agricultor, posto que, comumente, são cobradas taxas para os processos de regularização.

O secretário de Agricultura de um dos municípios afirmou: 
Sempre que se fala em regularizar, o agricultor pensa que isto envolverá em algum custo para ele; e como já é bastante onerado pelos custos da lavoura, acaba não procurando saber o que deve fazer ou como deve fazer.

Com relação ao apoio aos agricultores por parte do Estado, a visão dos agentes é de que o Estado mantém, de forma constante, a assistência técnica e os programas de apoio e subsídio, mas falta interesse por parte de alguns agricultores. Sobre o assunto, o secretário municipal de Agricultura esclarece:

A prefeitura de Viçosa tem programas como o recolhimento de embalagens de agrotóxicos, feito nas zonas rurais. Existem ainda programas, como a inscrição dos proprietários no CAR e programa de mecanização agrícola, em que a prefeitura licita terceiros que possuem as máquinas e subsidia o valor da hora de trabalho para os agricultores.

A falta de informação também foi mencionada pelos dois grupos como um fator que contribui para que as normas sejam descumpridas. Os agentes ambientais, entretanto, ressaltam as dificuldades que o Estado enfrenta para que as informações cheguem até os agricultores, pois, segundo eles, faltam técnicos que possam ir a campo e há lugares em que os veículos de comunicação não têm alcance. Os agentes destacaram, ainda, que existem vários perfis de agricultores, alguns deles mais participativos, frequentando as reuniões dos Conselhos Municipais, buscando informações na sede da Emater e em outros órgãos. Outros, porém, não gostam de participar ou têm dificuldade para sair da propriedade, pois, com frequência, representam a principal mão de obra da roça. O secretário municipal de Agricultura afirmou:

Existe um problema muito difícil de resolver. Muitas vezes, a prefeitura tem projetos, divulga por todos os meios possíveis - rádio, reuniões com as comunidades, jornais - mas, mesmo assim, essa informação não chega, porque existe uma parte dos agricultores que não participa das reuniões comunitárias e nem tem acesso a nenhuma dessas formas de divulgação. Tanto é verdade que já faz dois meses que a prefeitura está realizando o CAR; mas, na última semana, a demanda dobrou, e isto porque passou uma notícia sobre isto no Globo Rural. O Globo Rural é um programa que muitos agricultores assistem; mas por outros veículos de comunicação, às vezes, a informação não chega.

A fala do secretário faz referência a um estereótipo de agricultor que o identifica como pouco sociável e desengajado. Ao associar o camponês a tais características, o Estado, de certa forma, delega a ele, camponês, a responsabilidade por não acessar os benefícios públicos, pois é pessoa pouco aberta às ações destinadas à comunidade.

O promotor de Justiça associou a falta de informação dos agricultores à dificuldade destes para compreenderem os Termos de Ajustamento de Conduta que realizam com o Ministério Público. Nesse sentido, afirmou que, embora muitos agricultores aceitem o Termo, não conseguem cumpri-lo, e a consequência disso é a obrigatoriedade de o Ministério Público realizar a execução civil. A execução pressupõe iniciar uma ação judicial, e isso implica uma série de desdobramentos judiciais. Desse modo, se decorrido o prazo dado pela Justiça para que a pessoa cumpra o TAC, e ela não o fizer, inviabiliza-se a tentativa de resolver o problema de forma extrajudicial e inicia-se a fase judicial.

Sobre este aspecto acredita-se que o rebuscamento da linguagem forense acaba funcionando como uma forma de constranger o agricultor a aceitar, sem restrições, os acordos propostos. Posteriormente à realização do TAC, o agricultor percebe que aquilo que aceitou é extremamente oneroso e difícil de ser cumprido, permanecendo inerte em relação ao que foi acordado. Vencido o prazo, o Ministério Público, obrigado a exigir o cumprimento do compromisso firmado, inicia uma ação judicial. Bourdieu chama a atenção para o fato de o Direito ser um instrumento criado para ser usado apenas por especialistas. Ele afirma: "O desvio entre a visão vulgar do cliente e a visão científica do perito, juiz, advogado, etc., nada tem de acidental; ele é constitutivo de uma relação de poder" (BOURDIEU, 2003, p. 226). Evidencia-se, nesse caso, o uso do Direito como instrumento de poder.

Além da dificuldade para compreender a linguagem, outros fatores, como a própria sede física do poder Judiciário, a sua forma de funcionamento e até mesmo as vestes, comuns em ambientes judiciais, contribuem para intimidar o agricultor e induzi-lo a aceitar os acordos, apresentados, inclusive, como uma benevolência do Estado para resolver o problema de forma mais célere e mais simples. A esse respeito, Tragtenberg (1980) 
afirma que o Estado chega à população por meio do aparato burocrático, ou seja, de órgãos hierarquicamente organizados, com símbolos que os identificam ou distinguem, uniformes, formas de apresentação que, na verdade, representam uma forma de apresentação da burocracia como poder.

Essa forma de apresentação erudita e formalista dos órgãos judiciais contribui para intimidar o agricultor porque, além de transmitir, de forma subjacente, a noção de poder que a instituição possui e exerce representa o oposto daquilo a que o agricultor está acostumado, que é a simplicidade e a informalidade. Além disso, a apresentação do TAC como forma mais rápida e fácil de solucionar o problema evidencia a sua desvantagem diante daqueles que são responsáveis por propor o acordo. Os acordos extrajudiciais representam uma forma de "desafogar" o poder Judiciário. Cada acordo realizado é um processo a menos que tramitará. Em grande parte das vezes os agricultores aceitam a proposta sem compreendê-la ou compreendendo o que não têm condições de cumprir. A aceitação deve-se ao fato de eles já terem sido alertados de que a recusa conduzirá a um caminho ainda mais árduo, que é a via judicial.

As explicações da Polícia Militar Ambiental sobre as causas dos descumprimentos das normas concentraram-se na falta de severidade da lei ambiental. Os policiais enfatizaram que muitos agricultores conhecem a lei, mas preferem "correr o risco". Segundo eles, isso ocorre porque a lei ambiental é branda. Disse o sargento: "Muitos [agricultores] sabem o que é proibido, mas optam por correr o risco, porque o valor das multas é baixo."

No mesmo sentido foi o comentário do soldado: "Nós trabalhamos para torná-la efetiva, mas a lei ambiental é branda; e assim, ela acaba estimulando o crime".

O sargento da Polícia Ambiental comentou, ainda, que a lei, muitas vezes, é desproporcional à extensão do dano e que o melhor seria que o agente fiscalizador tivesse uma autonomia maior para dosar a pena. Nas palavras dele:

Acho que ela poderia dar um poder maior ao agente fiscalizador para que, no momento da fiscalização, ele pudesse avaliar as dimensões do impacto e aplicar a multa de acordo com essas dimensões.

A desproporcionalidade da multa administrativa foi mencionada, também, pelos agricultores. Vale lembrar a fala do senhor Antônio, da Pedreira (Viçosa, MG):

Eu limpei a capoeira, um pedacinho à toa, para plantar e tratar da família. Eles vieram aqui e me multaram. A multa foi a mesma do que se eu tivesse cortado tudo. Quando eles foram embora, eu fui lá e cortei o resto! Já tinha me multado mesmo! [risos].

Os parâmetros para aplicação das multas são estabelecidos em decreto. Apesar disso, cabe enfatizar que todos os órgãos da administração pública estão sujeitos ao princípio da proporcionalidade. De acordo com Cunha Júnior (2009, p. 50), "a proporcionalidade é um importante princípio constitucional que limita a atuação e a discricionariedade dos poderes públicos e, em especial, veda que a administração pública aja com excesso ou valendo-se de atos inúteis, desvantajosos, desarrazoados e desproporcionais". Representa, portanto, uma proteção do indivíduo contra o arbítrio do poder do Estado.

Confrontando as percepções dos agricultores com a dos agentes ambientais, o que se percebe é que ambos reconhecem que a lei ambiental é complexa e que a burocracia dificulta o seu cumprimento. Enquanto os agricultores, no entanto, queixam-se da falta de apoio por parte do Estado, o "Estado" tenta apresentar justificativas que atribuam a responsabilidade pelo descumprimento da lei ao próprio agricultor. Nota-se, assim, a existência de um paradoxo, pois se, por um lado, o Brasil conta com uma legislação ambiental moderna e inovadora, por outro essa legislação permanece desconhecida e desobedecida por uma considerável parcela de destinatários.

Ainda que haja previsões legais que visem a assegurar garantias ao cidadão diante do poder do Estado e que busquem enfatizar a existência de diferentes sujeitos de direito e de diferentes formas de tratamento que devem ser destinadas a eles, a ausência de políticas públicas, no sentido de capacitar tais indivíduos para que possam usufruir dos mecanismos de defesa, inviabiliza a sua utilização. Dessa forma, a modernização legislativa, para parte significativa dos destinatários da norma, permanece apenas no papel, visto que o acesso às medidas de proteção e de salvaguarda fica limitado aos que possuem mais capital econômico ou social (redes de relacionamento). 
Conforme afirma Souza (2006), as instituições, no Brasil, são modernas, mas isso não significa que elas sejam o reflexo de uma sociedade que se modernizou. A exclusão histórica dos agricultores pobres não terminou com os ciclos econômicos; ao contrário, permanece e se estende para outras áreas, como a política e a jurídica. Isso ocorre porque as instituições modernas representam uma criação da sociedade conservadora para assegurar direitos e garantias para os grupos dominantes. Assim, apesar da modernidade, os grupos dominados permanecem cobertos pela invisibilidade social e política, ocupando lugar periférico na sociedade.

\section{REFLEXÕES À LUZ DO "DIREITO À DIGNIDADE"}

De acordo com a doutrina jurídica, o patamar mínimo de que o cidadão necessita é compreendido como "mínimo existencial". Segundo Rawls (2001, p. 166), "abaixo de um certo nível de bem-estar material e social, e de treinamento e educação, as pessoas simplesmente não podem participar da sociedade como cidadãos e, muito menos, como cidadãos iguais". A dignidade humana, direito fundamental e princípio máximo do Estado Democrático de Direito, exige desse último não só respeito e proteção, mas garantia das condições existenciais mínimas para uma vida saudável.

A Constituição Federal ao estabelecer a dignidade humana como fundamento da República, coloca esse princípio como base de sustentação de toda a estrutura jurídica e social. Segundo Sarlet (2001), o conceito de dignidade é algo que não pode ser definido abstratamente, mas apenas em concreto, à luz de um determinado ordenamento jurídico e dos influxos históricos e culturais de cada sociedade. Toda essa dificuldade teórica em identificar com precisão o conteúdo da dignidade humana decorre do fato de ser tal conceito indeterminado, ou seja, por ser vago e subjetivo, exige do intérprete a concretização de seu significado (SARLET, 2001). O que se pode afirmar ao certo é que o elemento cultural é indissociável da noção de dignidade. Além disso, há que se considerar, ainda, que o conceito de dignidade tende a ser ampliado ou restringido por outros fatores, entre os quais o econômico. Assim, em uma sociedade economicamente mais desenvolvida, o conceito de dignidade - e, consequentemente, daquilo que a ofende - tende a ser mais alargado do que em outra menos desenvolvida (SARLET, 2001).

Sarlet (2001) observa que o Direito exerce papel crucial na proteção e na promoção da dignidade, embora ela não exista apenas onde é por ele reconhecida. Para o autor, quando se fala em "direito à dignidade", se está a considerar o direito ao reconhecimento, ao respeito, à proteção e a uma existência digna. Assim, ainda de acordo com Sarlet (2008), a dignidade possui uma dimensão dúplice, que se manifesta, por um lado, como expressão da autonomia humana, e, por outro, como objeto sobre o qual deverá recair a obrigatória proteção e respeito, tanto por parte do Estado como por parte da comunidade.

Conforme Sarlet (2008), a dignidade da pessoa humana manifesta-se, simultaneamente, como limite e tarefa dos poderes estatais e da comunidade em geral. Como limite, a dignidade implica não apenas que a pessoa não pode ser reduzida à condição de mero objeto da ação própria e de terceiros, mas também o fato de que a dignidade gera direitos contra atos que a violem ou a exponham a graves ameaças. Como tarefa da previsão constitucional da dignidade da pessoa humana, decorrem deveres concretos de tutela por parte dos órgãos estatais, no sentido de proteger a dignidade de todos, assegurando-lhes também o devido respeito e promoção (SARLET, 2008).

Nesse mesmo sentido, Bortoluzzi (2005) afirma que a dimensão tarefa do princípio resulta na imposição ao Estado, e também à comunidade, de preservar a dignidade existente, promovendo e criando condições que possibilitem o seu pleno exercício. Assim, surge como obrigação do Estado a função de promover as condições que viabilizem e removam todos os obstáculos que estejam impedindo pessoas de viverem com dignidade (BORTOLUZZI, 2005).

Quanto à dimensão limite, o princípio da dignidade humana implica uma obrigação geral de respeito pela pessoa, traduzida num feixe de deveres e direitos correlativos, de natureza não meramente instrumental, mas sim relativos a um conjunto de bens indispensáveis ao florescimento humano (BORTOLUZZI, 2005). Disso resulta que todos os órgãos, funções e atividades estatais ficam vinculados ao princípio da dignidade da pessoa humana, devendo todos agir com respeito e proteção. Isso posto, nem mesmo o Estado poderá fazer ingerências na esfera individual que sejam contrárias à dignidade pessoal. 
Dworkin (1998), ao tratar do conteúdo da dignidade humana, reporta-se à doutrina de Kant e relembra que o ser humano não poderá jamais ser tratado como objeto, ou seja, como mero instrumento para realização dos fins alheios. Por essa razão é que se impõe o seu reconhecimento e a sua proteção pela ordem jurídica, que deve zelar para que todos recebam igual consideração e respeito por parte do Estado e da comunidade, o que aponta para a dimensão política da dignidade (SARLET, 2008, p. 25).

De acordo com Taylor (2000), a filosofia, centrada na noção de dignidade, tem desenvolvido uma política do universalismo da igualdade entre todas as pessoas (a Declaração Universal dos Direitos Humanos é um exemplo dessa postura), na qual a igual dignidade dos cidadãos se tem resolvido em uma política cujos conteúdos têm sido a igualação de direitos e privilégios por meio da lei (TAYLOR, 2000). Concomitantemente a esse tipo de política anteriormente mencionado, contudo, também se desenvolveu, no mundo contemporâneo, uma política da diferença que, por vezes, entra em conflito com a da política da igualdade universal. A política da diferença surge em virtude da discriminação histórica de grupos minoritários ou marginalizados e prega que não é possível um ideal de igualdade universal, dadas as discrepâncias sociais e econômicas em que se encontram as diversas camadas sociais, o que implica que os grupos desfavorecidos historicamente lutam com desvantagens diante dos grupos dominantes.

Vale aqui ressaltar que, de acordo com Bourdieu (2003), com frequência as frações sociais dominantes mascaram a existência de desvantagem entre os grupos sociais diversos, e, principalmente, que este fato seja inerente ao exercício da dominação classista. Ou seja, negam que exista uma ideologia da igualdade que serve de base ao consenso social e político, obscurecendo as relações de desigualdade.

Embora os ordenamentos normativos não sejam capazes de conceder dignidade, por ser o seu significado muito mais amplo do que um conceito jurídico, a existência de grupos sociais em posição de desvantagem aumenta a responsabilidade do poder Judiciário, visto ser ele também responsável pela transposição do significado legal de dignidade para a realidade.

\section{CONSIDERAÇÕES FINAIS}

Conforme demonstrado, a posição de desvantagem dos agricultores familiares, que é nítida em termos sociais e econômicos, existe também nas relações judiciais. Por meio das análises processuais evidenciou-se a incapacidade de tais sujeitos utilizarem os mecanismos legais de defesa, como a defesa técnica realizada por advogado ou mesmo o acesso aos recursos. Nesse contexto, a lei funciona como um instrumento de poder e, como tal, em lugar de promover o tratamento equânime entre os diversos grupos sociais, amplia e reforça o histórico de exclusão, já existente nas esferas social e econômica. Confirma-se, portanto, a hipótese de pesquisa.

Apesar de a legislação e o próprio Judiciário reconhecerem a condição de vulnerabilidade do agricultor, não há medidas efetivas no sentido de corrigir o desnível, como a estruturação de órgãos (inclusive voluntários) que possam prestar assistência e oferecer apoio para viabilizar a defesa dos agricultores ou torná-la mais eficiente. Assim, as garantias constitucionais e legais, como o acesso aos recursos ou o direito de ser tratado com dignidade ou de receber uma pena proporcional à gravidade da conduta praticada acabam ficando apenas no papel.

À luz do "direito à dignidade" pode-se compreender que cabe ao poder público, em todas as suas esferas, buscar agir para assegurar que todo cidadão seja tratado com respeito, que lhe sejam resguardadas as garantias mínimas de tratamento equânime e respeitadas suas características particulares.

\section{REFERÊNCIAS}

BORTOLUZZI, Roger Guardiola. A dignidade da pessoa humana e sua orientação sexual. As relações homoafetivas. Jus Navigandi [website jurídico], publ. mar. 2005. Disponível em: https://jus.com.br/artigos/6494/a-dignidade-da-pessoa-humana-e-sua-orientacao-sexual. Acesso em: 3 abr. 2005.

BOURDIEU, Pierre. O poder simbólico. Trad. Fernando Tomaz. 6. ed. Rio de Janeiro: Bertrand Brasil, 2003. (Coleção Memória e Sociedade).

BRASIL. Constituição da República Federativa do Brasil, de 5 de outubro de 1988. Brasília, DF, 5 out. 1988. Disponível em: http://www.planalto.gov.br/ccivil_03/Constituicao/Constituiçao.htm. Acesso em: 2 abr. 2020. 
BRASIL. Lei no 12.651, de 25 de maio de 2012. [Código Florestal]. Dispõe sobre a proteção da vegetação nativa; altera as Leis nos 6.938, de 31 de agosto de 1981, 9.393, de 19 de dezembro de 1996, e 11.428, de 22 de dezembro de 2006; revoga as Leis nos 4.771, de 15 de setembro de 1965, e 7.754, de 14 de abril de 1989, e a Medida Provisória no 2.166-67, de 24 de agosto de 2001; e dá outras providências. Diário Oficial da União (DOU). Brasília, DF, Seç. 1, p. 16, 28 maio 2012 (Veto). Disponível em: http://www.planalto.gov.br/ccivil_03/_ato2011-2014/2012/lei/l12651.htm. Acesso em: 2 abr. 2014.

CORRÊA, João Batista Lúcio. Quantificação das áreas de preservação permanente e reserva legal e de seus impactos econômicos na bacia do Rio Pomba em Minas Gerais. 2004. 79f. Dissertação (Mestrado em Ciência Florestal) - Universidade Federal de Viçosa. Viçosa, MG, 2006.

CUNHA JÚNIOR, Dirley da. Curso de Direito Administrativo. 7. ed. Salvador: Juspodvim, 2009.

DEWEY, John. Liberalismo, liberdade e cultura. Trad. Anísio Teixeira. São Paulo: Nacional, 1970.

DWORKIN, Ronald. El dominio de la vida. Una discusión acerca del aborto, la eutanasia y la liberdad individual. Barcelona, ES: Ariel, 1998.

DWORKIN, Ronald. O império do direito. Trad. Jefferson Luiz Camargo. 2. ed. São Paulo: Martins Fontes, 2007.

FLEURY, S. Estado sem cidadãos: seguridade social na América Latina [on-line]. Rio de Janeiro: Editora Fiocruz, 1994.252 p. ISBN 85-85676-06-X. Disponível em: http://books.scielo.org. Acesso em: jun. 2016.

FREIRE, Paulo. Pedagogia do oprimido. Rio de Janeiro: Paz e Terra, 1983.

IHERING, Rudolf von. A luta pelo direito. Trad. e apres. Richard Paul Neto. Rio de Janeiro: Editora Rio, 1978.

NAVARRO, Zander; PEDROSO, Maria Theresa M. A agricultura familiar no Brasil: da promessa inicial aos impasses. Rev. Econ. $N E$, Fortaleza, v. 45, suplemento especial, p. 7-20, out./dez. 2014.

NIEDERLE, Paulo André; GRISA, Catia. Diversificação dos meios de vida e acesso a atores e ativos: uma abordagem sobre a dinâmica de desenvolvimento local da agricultura familiar. Cuadernos de Desarrollo Rural, v. 5, n. 61, p. 41-69, jul./dic. 2008.

RAWLS, J. Justice as Fairness: a restatement. Cambridge: Harvard University Press, 2001.

SARLET, Ingo Wolfgang. A eficácia dos direitos fundamentais. Uma teoria geral dos direitos fundamentais na perspectiva constitucional. 2. ed. Porto Alegre: Livraria do Advogado, 2001.

SARLET, Ingo Wolfgang. Dignidade da pessoa humana e direitos fundamentais na Constituição Federal de 1988. 6. ed. Porto Alegre: Livraria do Advogado, 2008.

SOUZA, Jessé. A construção social da subcidadania: para uma sociologia política da modernidade periférica. Belo Horizonte, MG: Editora da UFMG, 2006.

TAYLOR, Charles. Argumentos filosóficos. São Paulo: Loyola, 2000.

TRAGTENBERG, Maurício. Burocracia e ideologia. 2. ed. São Paulo: Unesp, 1980.

VAN DER PLOEG, Jan D. Sete teses sobre a agricultura camponesa. In: PETERSEN, Paulo (org.). Agricultura familiar camponesa na construção do futuro. Rio de Janeiro: AS-PTA, 2009. p. 17-31.

WOORTMANN, Klass. "Com parente não se neguceia" - o campesinato como ordem moral. Brasília: Editora Universidade de Brasília; Tempo Brasileiro , 1990. 